\title{
RITUAL YA QOWIYU: Pergulatan Makna Modernitas, Agama, Budaya Lokal dan Kapitalisme
}

\author{
Mohammad Hasan Basri \\ Anggota lembaga kajian CFSS (Center for Figh and Society Studies) Yogyakarta. \\ e-mail: hasanbasri@gmail.com
}

Abstract

In this article, the writer tries to analyze the contrast between modernity, religion, and culture. Shortly, the contrast between religious teaching (Islam) taught by Ki Ageng Gribig, modernity, and culture (Javanese) is shown in the rituals and social-economic life (capitalism spirit) of Jatinom Society, both symbolically and practically. The contrast and meaning relation of the three domains not only result in conflict, tension, and resistance but also relation and new interpretation among the members of society, so that the celebration is held annually. Therefore, the process of interpretation and the different economic, social, cultural, and politic influences will continue from time to time to match with the change experienced by Jatinom society specifically and the population around the area generally. The process of interpretation on religion has changed because of its contrast with the value of modernity. In Jatinom society, the religious process has been formed and influenced by modernity ideas, such as, the process of rationalization on the rituals, that is, the decrease of their belief in 'blessing' in apem, but on the other side, they still preserve the rituals to honor their ancestors and customs. They also think that it is economically beneficial because of the visit of thousands of people in the celebration.

Key words: rituals, blessing, capitalism. 


\section{Pendahuluan}

Secara historis, tradisi perayaan ya qowiyu di Jatinom, Klaten Jawa Tengah, berawal dari sebuah apem (sejenis kue yang terbuat dari tepung dan santan kelapa) yang dibagikan oleh Ki Ageng Gribig (salah satu Keturunan Sunan Giri) kepada para tetangga dan penduduk sekitar sebagai pengganti oleh-oleh dari tanah suci Makkah ketika ia menunaikan ibadah haji. Apem tersebut dipercaya oleh masyarakat secara turuntemurun bisa membawa berkah bagi kehidupan mereka baik dalam kehidupan rumah tangga, kesehatan, pertanian, dan lain-lain. Sehingga ritual yang biasa juga disebut perayaan apeman ini tiap tahun tetap diselenggarakan oleh masyarakat. Sedangkan istilah ya qowiyu adalah berasal dari doa Kiai Ageng Gribig, seorang penyebar agama Islam abad ke-14 yang dibaca di setiap akhir pengajian yang dihadiri oleh penduduk Jatinom. Doa tersebut lengkapnya berbunyi "Yaa Qowiyu Yaa Aziz Qowwina wal muslimin, Yaa Qowiyu Yaa Rozzaq warzuqna wal muslimin" (Ya Tuhan Yang Maha Kuat, berikanlah kekuatan kepada kami dan kaum muslimin, Ya Tuhan Yang Maha Kuat dan Tuhan Yang Maha Pemberi Rezeki, berikanlah rezeki kepada kami dan kaum muslimin). Doa ini dibaca pertama kali ketika beliau pulang dari tanah suci Makkah untuk menunaikan ibadah haji. Menurut catatan, kepulangannya bertepatan dengan hari Jum'at tanggal 15 Bulan Safar 1511 kalender Jawa atau 1589 Masehi, sehingga sampai saat ini perayaan ya qowiyu ini diselenggarakan sesuai dengan tanggal tersebut.

Tulisan singkat ini tidak akan mengupas secara detail prosesi perayaan apeman, namun lebih kepada tinjauan sosiologis bagaimana ritual itu mempengaruhi, merubah ataupun membentuk struktur masyarakat Jatinom dan sekitarnya. Penulis mencoba menjelaskan ritual apeman ini dengan menggunakan teori modernitas, agama, dan budaya nenek moyang (Bernard, 2004: 251-267), serta analogi ide protestanisme terhadap munculnya kapitalisme dengan kepentingan pasar yang ada di perayaan apeman (Johnson, 1994: 207-249). 


\section{Agama dan Spirit Kapitalisme}

Begitu sampai di tempat perayaan ya qowiyyu, satu hal yang membuat saya merasa takjub adalah berjubelnya ribuan pengunjung yang datang dari berbagai wilayah. Di sepanjang jalan menuju lokasi perayaan, sekilas memang nampak begitu banyak orang-orang pergi ke sana. Namun di balik berjubelnya para pengunjung tersebut, di kanan-kiri sepanjang jalan menuju lokasi, berderet kios-kios dan pedagang kaki lima memajangkan dagangannya, mulai dari makanan, mainan anak-anak, busana sampai berbagai macam souvenir bisa kita dapatkan. Dari besarnya jumlah pengunjung bisa dibayangkan potensi pasar selama perayaan tersebut. Melihat potensi tersebut benarkah perayaan tersebut hanya semata-mata "memperoleh berkah" seperti kepercayaan awal perayaan ini diselenggarakan. Ada banyak pihak yang memanfaatkan potensi pasar ini demi meraup keuntungan, mulai dari pedagang bakul sampai perusahaan nasional seperti perusahaan rokok. Secara ekonomis, masyarakat Jatinom memang diuntungkan dengan perayaan apeman ini, karena secara otomatis pendapatan mereka bertambah. Dengan kata lain, ada persinggungan agama dengan spirit kapitalisme (Weber, 1998: 45).

Walaupun Weber keburu meninggal sebelum menyelesaikan monograf Islam kaitannya dengan kapitalisme, namun tidak berlebihan kiranya bila kita hubungkan tradisi Islam dengan besarnya kepentingan ekonomi dalam perayaan apeman ini. Hal ini bisa dikaitkan dengan pandangan Weber bahwa Protestanisme memang merangsang munculnya kapitalisme pada tahap-tahap awal, namun tidak berarti bahwa kapitalisme itu terus-menerus membutuhkan legitimasi agama. Sesudah kapitalisme itu berdiri, dia menjadi otonom dan berdikari tanpa membutuhkan dukungan agama. Dengan demikian, yang ada dibalik ritual adalah kecenderungan pengembangan ekonomi yang bercorak kapitalis berbanding lurus atau bertemu dengan perubahan pandangan masyarakat bahwa kepentingan ekonomi lebih mengedepan daripada mementingkan makna ritual itu sendiri. Mereka mempertahankan ritual tersebut bukan semata-mata melestarikan tradisi dan agama, namun juga kepentingan ekonomis (Weber, 1991: 84). 


\section{Resistensi Agama dan Budaya Lokal}

Selain persinggungan agama dan spirit kapitalisme, dalam ritual ini juga terdapat resistensi budaya lokal dengan ide purifikasi nilai-nilai agama. Kepercayaan masyarakat Jatinom sendiri terhadap makna ritual ini memang sudah luntur, dalam artian bahwa mempercayai keberkahan dari apem merupakan bentuk kemusyrikan (tidak mengesakan Tuhan lagi) yang dilarang keras oleh agama.

Dengan demikian, di satu sisi, masyarakat Jatinom sebenarnya sudah tidak mempercayai atau mungkin bahkan menganggap ritual ini tidak begitu penting bagi keberagamaan mereka karena sudah tidak sesuai dengan pemahaman keagamaan mereka. Namun di sisi lain, jika perayaan ini tidak lagi dirayakan bisakah mereka mendapatkan penghasilan besar seperti yang diperoleh dari perayaan ini walaupun hanya sehari.

\section{Budaya dan Kekuasaan}

Hal lain yang menarik untuk diamati dari perayaan apeman ini adalah pertarungan kepentingan dan kekuasaan baik di tingkat lokal desa Jatinom maupun kekuatan dan pengaruh kerajaan Yogyakarta dan pemerintah daerah terhadap penyelenggaraan apeman ini.

Di tingkat lokal, perebutan pengaruh dan peran dalam sosial keberagamaan masyarakat Jatinom, walaupun agak kurang tepat saya memetakannya, adalah pengaruh kalangan tradisionalis dan kalangan modernis. Menurut salah satu panitia yang juga mewakili kaum modernis mengatakan bahwa pernah terjadi pertentangan dalam persoalan penyelenggaraan apeman ini, menurut kalangan tradisionalis penyelenggaran apeman merupakan sebuah bentuk pelestarian tradisi dan budaya yang dibawa oleh Ki Ageng Gribig namun menurut kalangan modernis kepercayaan terhadap apem tersebut merupakan bentuk syirik yang dapat merusak iman dan pengesaan kepada Tuhan.

Kemudian, kekuatan kerajaan juga bisa diamati melalui prosesi apeman; bentuk apeman yang diarak menuju tempat "pelemparan" (karena proses pembagian apem dilakukan dengan dilempar dari atas menara) sama dengan dua gunungan besar yang terdiri dari gunungan lanang dan gunungan wadon 
(Suara Merdeka, 2006: 3). Itu biasa digunakan dalam setiap perayaan di keraton, padahal secara historis pengaruh Ki Ageng Gribig dulu lebih kuat dari Raja, karena sering menjadi penasihat bahkan menjadi penentu bagi kebijakan kerajaaan Mataram saat itu ketika ia diutus ke Palembang untuk menggagalkan pemberontakan (Panitia Ya Qowiyu, 1953: 8-10). Dengan demikian, bisa dikatakan bahwa ada upaya keraton untuk merebut pengaruh dan memperkuat patronase masyarakat Jatinom kepada kerajaan Yogyakarta.

Kekuatan lain yang juga masuk dalam proses perayaan apeman adalah pihak Dinas Pariwisata. Hal ini bisa kita lihat dari komposisi panitia penyelenggara ritual ini, walaupun juga melibatkan kalangan mahasiswa Institut Seni Indonesia dan pemuda desa Jationom, secara koordinatif dan finansial yang memegang peranan penting tetap dari pihak Pemda. Pengaruh pemerintah daerah ini juga bisa diamati melalui prosesi arak-arakan dua gunungan apem menuju lokasi pelemparan di mana yang mengiringi dan memulai pelemparan apem ke ribuan pengunjung adalah Bupati.

\section{Simpulan}

Dari proses perayaan Ya Qowiyyu di atas secara teoretis dapat disimpulkan ada persinggungan antara modernitas, agama, dan budaya nenek moyang. Secara singkat dapat dijelaskan bahwa persinggungan antara ajaran agama (Islam) yang dibawa oleh Ki Ageng Gribig, modernitas, dan budaya (Jawa) tergambar dalam ritual dan kehidupan sosial-ekonomi (spirit kapitalisme) masyarakat Jatinom, baik secara simbolik maupun praktik. Persinggungan dan jaringan makna ketiga domain tersebut yang berjalan berkelindan tidak hanya menimbulkan pertentangan, ketegangan, dan resistensi namun juga pertemuan dan pemaknaan baru di antara elemen masyarakat, sehingga perayaan tersebut tetap dijalankan setiap tahun. Sehingga secara terus-menerus akan mengalami proses pemaknaan dan pengaruh ekonomis, sosial, kultural dan politik yang berbeda terhadap perubahan masyarakat Jatinom secara khusus maupun penduduk sekitar secara umum.

Proses pemaknaan agama telah mengalami perubahan karena persinggungannya dengan nilai-nilai modernitas; bagi masyarakat Jatinom, proses keberagamaan mereka telah dibentuk dan dipengaruhi oleh ide-ide modernitas seperti proses 
rasionalisasi terhadap ritual yakni mulai memudarnya kepercayaan akan adanya "berkah" dalam apem, namun di sisi lain mereka tetap melestarikan ritual tersebut karena untuk menghormati nenek moyang, serta adat mereka (Bernard, 2004: 253-259). Mereka juga merasa diuntungkan secara ekonomis, dengan ribuan orang yang datang keperayaan tersebut bisa dibayangkan betapa besarnya potensi ekonomi yang bisa diraih. Tidak hanya bagi masyarakat Jatinom sendiri, tetapi pihak lain seperti para pengusaha, birokrasi dan pemerintah daerah telah terpikat juga untuk meraup keuntungan dari perayaan Ya Qowiyu tersebut (Johnson, 1994: 231-232).

\section{Daftar Pustaka}

Bernard, Adeney Risakotta. 2004. Modernitas, Agama dan Budaya Nenek Moyang: Suatu Masyarakat Indonesia. Dalam Sociology of Religion Reader. Yogyakarta: CRCS-UGM.

Johnson, Doyle Paul. 1994. Teori Sosiologi Klasik dan Modern. Terjemahan oleh Robert M.Z. Lawang. Jakarta: Gramedia.

Kuper, Adam. 2000. Ensiklopedi Ilmu-ilmu Sosial. Jakarta: PT. Raja Grafindo Persada. Panitia Ya qowiyu (Dinas Pariwisata Kabupaten). 1953. Riwayat Kiai Ageng Gribig. Yogyakarta: [penerbit tidak diketahui].

Weber, Max. 1991. The Sociology of Religion. Boston: Beacon Press.

Weber, Max. 1998. The Protestant Ethic and The Spirit of Capitalism. Terjemahan oleh Talcott Parsons. California: Roxbury Publishing Company.

www.suarakarya-online.com.news.html.id. [13 Maret 2006].

www.suaramerdeka.com. nas14.htm. [13 Maret 2006]. 